Fanum

Sociológico

\section{Forum Sociológico}

Série II

$20 \mid 2010$

A pobreza, pluralidade de olhares e de intervenções

\title{
Precários voláteis e trajectórias de emprego em carrossel, o caso dos beneficiários do RSI
}

\section{Fernando Diogo}

\section{(2) OpenEdition \\ 1 Journals}

\section{Edição electrónica}

URL: https://journals.openedition.org/sociologico/90

DOI: $10.4000 /$ sociologico.90

ISSN: 2182-7427

\section{Editora}

CICS.NOVA - Centro Interdisciplinar de Ciências Sociais da Universidade Nova de Lisboa

\section{Edição impressa}

Data de publição: 1 junho 2010

Paginação: 29-38

ISSN: 0872-8380

\section{Refêrencia eletrónica}

Fernando Diogo, «Precários voláteis e trajectórias de emprego em carrossel, o caso dos beneficiários do RSI», Forum Sociológico [Online], 20 | 2010, posto online no dia 05 setembro 2012, consultado o 31 março 2022. URL: http://journals.openedition.org/sociologico/90 ; DOI: https://doi.org/10.4000/ sociologico.90

\section{Este documento foi criado de forma automática no dia 31 março 2022.}

(C) CICS.NOVA 


\title{
Precários voláteis e trajectórias de emprego em carrossel, o caso dos beneficiários do RSI
}

\author{
Fernando Diogo
}

\section{Introdução: a precariedade no contexto das transformações na esfera do trabalho}

1 A noção de precariedade no emprego surge em França, no início dos anos 80, inicialmente associada ao conceito de exclusão social e só mais tarde aplicada à esfera do trabalho (Barbier, 2002: 3 e 2005). A similitude dos ordenamentos jurídicos, no que ao trabalho e à protecção social respeita, levou a que se tenha espalhado aos países latinos $^{1}$ (Barbier, 2005: 352).

2 Contudo, mesmo nos países latinos, existem especificidades legislativas que os diferenciam (Barbier, 2002: 2 e 4), com efeitos na forma como as teorias e noções procuram ler a realidade (Diogo, 2003). Ora, o Estado português caracteriza-se por ser relativamente fraco no contexto europeu (Santos, 1993) e essa debilidade abre espaço a formas de regulação da relação laboral assentes nos interesses e nos costumes, à margem da regulação estatal e dos direitos de cidadania. Neste sentido, as teorias elaboradas para outros contextos sociais e económicos não dão conta destas especificidades portuguesas, associadas à precariedade do emprego.

3 Neste texto, procuramos rever a noção de precariedade no emprego, contextualizandoa na situação portuguesa, e aplicando-a a uma população em que a precariedade assume as formas mais diversas, os indivíduos em situação de pobreza.

4 Emprego precário opõe-se a emprego fixo, sem termo, seguro. Define-se, pois, a precariedade, por exclusão de partes: é precário o que não é permanente ou efectivo, o que sai fora da norma. Contudo, Rebelo (2002: 76) aponta um problema a esta definição: inclui formas de emprego que não são, necessariamente, precárias. A autora dá como 
exemplo o auto-emprego e o trabalho a tempo parcial, considerando que podem ser opções com garantias sociais dentro da norma.

Não obstante a pertinência da crítica, consideramos que não se deve descartar esta definição, por três razões:

Em primeiro lugar, tendo em conta o seu carácter involuntário (Kovács, 2005a: 2-3). Os indivíduos optam pelo emprego precário porque não têm melhor escolha. A consideração deste critério na definição do que é a precariedade, por si só, afasta os problemas associados à definição como precário de todo o emprego fora da norma.

7 Em segundo, os empregos precários estão, normalmente, associados a baixos rendimentos e, além disso, a uma redução dos direitos sociais dos trabalhadores, quando não mesmo à sua ausência (Santana e Centeno, 2000: 25-26; Rebelo, 2004: 43; Kovács, 2005a: 2-3; Duarte, 2009: 44; e Dornelas et al., 2010: 10).

8 Por último, uma definição sofisticada de precariedade dificilmente será operacionalizável e, como tal, é inútil, quer para conhecer a extensão e intensidade deste processo social, quer para servir de base à definição de políticas de intervenção social. Por si só, o argumento da operacionalização não é suficiente, mas associado às questões do carácter involuntário da relação laboral precária e à concomitante escassez de rendimentos (e de direitos sociais) representa um factor de peso na opção pela definição acima apresentada.

9 A precarização do emprego nas sociedades ocidentais é um processo em crescimento, afectando, ao mesmo tempo, categorias sociais antes protegidas. Desta forma, aumenta a sua importância social, política e mediática, justificando a crescente relevância científica desta problemática.

10 Este processo está associado a importantes transformações na esfera do trabalho que o contextualizam. Para Ulrich Beck, o trabalho adquiriu na nossa sociedade uma importância sem paralelo na história, sendo, juntamente com a família, o principal eixo da vida (2005: 139) ${ }^{2,3}$. Também Castel (1995) assume a importância do trabalho e da família no contexto das sociedades modernas, ao defender que a desafiliação e a integração dos indivíduos na sociedade se constroem na intercepção entre ambos.

11 Quer dizer, qualquer transformação na sociedade que envolva a esfera do trabalho tem amplas repercussões, tanto a nível macrossocial como na vida dos indivíduos (Beck, 2005: 140; Bresson, 2007: 51).

12 De entre as transformações que estão a ter lugar na esfera do trabalho, assume particular relevo, pelo seu impacto na sociedade, em primeiro lugar, a afirmação do desemprego de massa (Castel, 2009) como uma característica persistente da paisagem laboral das sociedades actuais. Este processo enraizou-se a partir dos anos $70 \mathrm{e}$, com flutuações em função dos ciclos económicos, tem vindo a manter-se (Castel, 2009: 13). Um segundo processo de grande impacto respeita à emergência da própria precariedade no emprego como fenómeno transversal às sociedades desenvolvidas, também nos anos 70 (Rebelo, 2002: 74 e 2004: 35; Fullerton e Wallace, 2007: 201 e 202; Kóvacs, 2005a: 1; e Castel, 2009: 162).

13 Para Beck (2005: 143), as alterações na contratação, no horário de trabalho e no local de trabalho têm vindo a criar uma situação em que o emprego a tempo inteiro com duração indeterminada num dado local é substituído por “(...) um sistema de subemprego flexível, de risco máximo, pluralizado, descentralizado". Este novo sistema de subemprego implica que boa parte dos desempregados adiram a estas novas formas 
de ocupação no pressuposto de que mais vale um mau emprego do que o desemprego, levando, assim, à redução da visibilidade social e estatística do desemprego (Beck, 2005: 143).

14 Castel (2009), numa análise mais recente, complementa e aprofunda esta perspectiva. 0 autor considera, como Beck, que estamos a atravessar uma fase de grandes transformações sociais no âmago do próprio sistema capitalista (idem: 11 e 13), caracterizada pela redução das oportunidades de ascensão social (idem: 12). Esta redução das oportunidades está ligada a importantes transformações no relacionamento dos indivíduos com a esfera do trabalho, onde se destaca a perda das garantias sociais associadas ao emprego (idem: 32 ).

ema mudança tanto mais fundamental quanto "o emprego estável e protegido tem constituído a base de construção da solidariedade na sociedade assalariada" (Castel, 2009: 159). As mutações na esfera do emprego e do trabalham passam, em larga medida, pela transformação da natureza do emprego, em particular com a diluição das fronteiras entre emprego e desemprego, criadoras de situações de subemprego ${ }^{4}$ (Beck, 2005: 142; e Castel, 2009: 161-162).

16 Assim, para um número crescente de indivíduos, o acesso à actividade laboral é feito através de formas de emprego fora da norma, fracamente protegidas em termos sociais (Castel, 2009: 172). O resultado é o surgimento de um conjunto de posições intermédias entre emprego e não emprego ${ }^{5}$, algumas das quais vão no sentido da coacção, por parte do Estado, para que os indivíduos assumam actividades desvalorizadas (idem: 171). A este propósito, tenha-se em consideração a pressão social a que se assiste em Portugal para coagir os beneficiários do RSI a trabalhar a troco da prestação.

17 A questão que se coloca não é a do declínio do trabalho, como defende Beck (2005) e critica Castel, mas a da transformação do trabalho. Assistimos, não ao fim do trabalho, mas a uma "valorização quase histérica do trabalho" (Castel, 2009: 53 e 171). Quer dizer, o que está em causa tem a ver com a relação jurídica dos indivíduos com o trabalho, com a persistência do desemprego de massas e a degradação do vínculo de efectivo, com a emergência de novas formas intermédias entre emprego e não emprego. Não obstante, esta não é apenas uma mudança objectiva, ao nível das formas contratuais, é também uma mudança ao nível dos valores sociais, em que valores concorrentes com o trabalho, como princípio definidor dos indivíduos, se afirmam (Sainsaulieu, 1998; e Bresson, 2007: 63). Estas novas formas de valorização de si criam uma tensão identitária forte nos indivíduos: por um lado, a sociedade continua a valorizar fortemente o trabalho, por outro lado, ao nível individual, afirmam-se possibilidades de os indivíduos se definirem para si e para os outros fora da esfera do trabalho (Diogo, 2007a).

\section{A pluralidade dos tipos de precariedade, contributos para uma tipologia}

18 A precariedade no emprego remete-nos para a ideia de incerteza face ao futuro numa área central da vida humana. Contudo, pode assumir formas diversas, afectando categorias e grupos sociais distintos. Em primeiro lugar, a certeza de que, num prazo conhecido, a relação laboral terminará e, com ela, a fonte de rendimento para o indivíduo em questão, assim como para os que dele dependem. Esta forma de abordar a precariedade remete-nos, sobretudo, para uma análise do vínculo laboral, sob as figuras 
de contrato de trabalho a termo certo e avença. Rebelo (2004: 45) designa este tipo como "precariedade legal", embora algumas das situações aqui consideradas também possam ser enquadradas no que esta autora designa por "precariedade ilegal".

Por outro lado, existe uma forma de precariedade insuficientemente estudada e, muitas vezes, esquecida. Referimo-nos à precariedade associada a formas de contratação tradicionais, típicas em sectores como a pesca, a agricultura, os serviços pessoais e domésticos que, no contexto português, nunca desapareceram totalmente.

Esta forma de precariedade, consubstanciada em contratos quase sempre orais, à tarefa, à peça, ao dia, assume particular importância entre os indivíduos em situação de pobreza (Diogo, 2007a), constituindo formas de subemprego estrutural, porque persistentes no tempo e associadas à maneira como o mercado de trabalho se organiza no nosso país. Esta é, pois, uma precariedade tradicional, associada à economia informal e ao desrespeito pelas regras de contratação legais, uma forma de "precariedade ilegal", no dizer de Rebelo (2004: 45). Contudo, tende a ser ignorada, dado que não é mencionada nas construções teóricas provenientes de outros países. Simplesmente, é residual nesses contextos nacionais, é, em boa parte, uma especificidade portuguesa. Além disso, constitui o que podemos designar como uma cifra negra, ou cifra cinzenta, dado que é muitas vezes invisível ao aparelho estatístico, dada a sua informalidade e ilegalidade.

21 Mas a precariedade também pode ser vista a partir da ameaça sentida para com uma relação laboral juridicamente segura (Bourdieu, 1993; e Gaulejac e Léonetti, 1994; Duarte, 2009: 45), algo a que está associada a ideia do desemprego eminente por possibilidade de falência da empresa, deslocalização, reestruturação (em particular o downsizing), ou ainda pelo outsourcing.

Rebelo (2004: 51 e 53-55) chama-nos a atenção para a influência da reduzida dimensão média das empresas portuguesas nesta forma de precariedade, dado que mesmo um trabalhador com um contrato sem termo, numa pequena empresa em situação de fragilidade, não se encontra na mesma situação que outro trabalhador, com um vínculo semelhante, mas protegido pela dimensão e capacidade da sua empresa.

Trata-se, pois, da precariedade subjectiva (Rebelo, 2002; e Fullerton e Wallace, 2007: 202). Os trabalhadores vivem na incerteza do seu futuro como empregados, mau grado a solidez formal do seu vínculo laboral.

Os tipos de precariedade aqui referidos, a precariedade objectiva, associada à contratação informal, aos empregos a prazo, avenças, recibos verdes e a formas tradicionais de contratação, e a precariedade subjectiva, relacionada com os empregos ameaçados por processos de falência ou reestruturação, remetem-nos para a incerteza face à sobrevivência futura. Desta maneira, e abstraindo dos diferentes entendimentos em causa, a incerteza da futura relação laboral é o denominador comum que permite agrupar sob o mesmo conceito situações aparentemente diferenciadas.

Finalmente, a proliferação das formas intermediárias entre emprego e desemprego, como os estágios, os empregos protegidos, os programas ocupacionais, etc., leva a uma nova forma de precariedade associada à ambiguidade de estatuto jurídico e social face ao emprego (Schnapper, 1989; Castel, 1995; Rebelo, 2004: 43-44) e, mais uma vez, à redução de direitos sociais associados ao emprego e a menores salários. 


\section{Precariedades múltiplas}

Existe um conjunto de temas com os quais se pode confrontar e relacionar a noção de precariedade no emprego, de modo a compreender o seu alcance heurístico ${ }^{7}$.

\section{Precariedade no emprego, exclusão social e pobreza}

27 A precariedade laboral não se distribui de forma uniforme pelo tecido social, tendendo a concentrar-se nas classes mais baixas. $O$ emprego, enquanto conjunto de benefícios sociais, desempenha um papel central na definição do lugar do indivíduo na sociedade, e um emprego de má qualidade (isto é, penoso, perigoso, precário, com baixa remuneração e com baixo prestígio social) relega os indivíduos para as margens, ou mesmo para fora dos modos de vida socialmente aceites e desejáveis numa dada sociedade, ou seja, para situações de exclusão social e pobreza.

8 É pertinente distinguir entre a precariedade associada às classes mais baixas, que é a que nos interessa, e outras formas de intermitência no trabalho, respeitando aos profissionais liberais. Estes diferenciam-se pelos vencimentos, mas também pela escolaridade, pela profissão, e pela existência de uma carreira informal, à medida que o seu reconhecimento aumenta vão obtendo mais trabalhos e mais bem pagos (pelo menos potencialmente).

29 Contudo, uma fracção cada vez maior destes profissionais mais qualificados encontra-se em situação de precariedade no emprego, tal como a temos vindo a discutir. $\mathrm{O}$ que os diferencia dos outros profissionais e os aproxima das categorias sociais tradicionalmente mais vulneráveis são as características que constroem a vulnerabilidade: a escassez de rendimentos, a inexistência da carreira (informal), a relegação para actividades menos reconhecidas socialmente (no contexto das suas profissões), o subemprego ${ }^{8}$, ou a degradação das regalias sociais associadas ao emprego sem termo...

\section{Precariedade e carreira}

30 A precariedade ganha em ser definida como uma trajectória de emprego em carrossel, marcada por mudanças sucessivas entre empregos sem estabilidade, penosos, perigosos e (eventualmente) o desemprego.

31 Esta última forma de ver a precariedade tem a vantagem de, conservando a ideia de incerteza em relação ao futuro, analisar esta problemática como um processo e não como um fenómeno. Isto é, permitindo separar as situações de precariedade circunscritas no tempo das que se prolongam de forma mais ou menos persistente.

A ideia de carrossel associada ao emprego é bem a antítese da noção de carreira. Há um recomeçar contínuo de um percurso profissional que se define mais pelas ausências do que por características próprias: ausência de progressão salarial, ausência de um aumento das responsabilidades, ausência de um aumento do prestígio na organização associado à subida de mais um degrau na carreira, ausência do aumento da satisfação associado à ideia de progresso pessoal e às tarefas desempenhadas. Nenhum dos benefícios materiais, sociais e simbólicos associados a uma carreira numa empresa ou numa profissão está à disposição dos indivíduos que desenvolvem uma trajectória de 
emprego em carrossel. Por muito que os indivíduos mudem, de emprego ou de profissão, ao longo da sua trajectória, não abandonam o mesmo lugar de classe.

\section{Alguns dados sobre a precariedade em Portugal}

\section{O contexto da precariedade em Portugal}

Os dados existentes sobre a precariedade no emprego devem ser lidos com cautela. Desde logo, porque as comparações internacionais são limitadas por legislações e práticas laborais muito distintas, pela dificuldade de definir o que é a precariedade, pelo reduzido número de estudos centrados nesta problemática, onde se procede à recolha de dados sobre o assunto, pelo próprio facto de esses dados não serem compagináveis, em alguns casos, com as estatísticas oficiais e, finalmente, porque boa parte da precariedade laboral, em Portugal, está à margem da lei e, como tal, das fontes estatísticas.

Não obstante, os dados existentes são a única forma de contextualizar este processo social, a sua incidência e amplitude.

Gráfico 1 Taxas de emprego, \% de contratos a termo (EU 27)

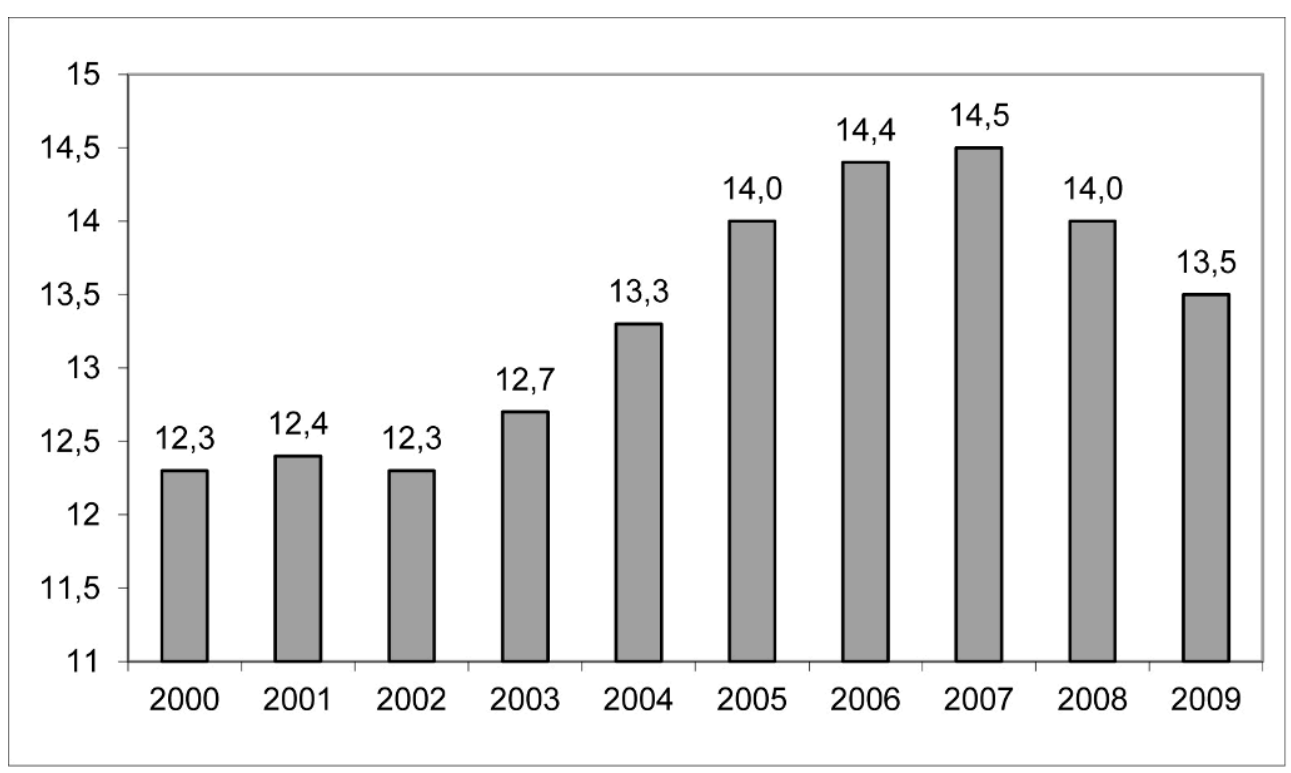

FONTE: Labour Force Survey (Eurostat)

No contexto da União Europeia a 27, podemos constatar uma tendência de aumento do número de contratos a termo no total do emprego, embora com uma inflexão desta tendência nos dois últimos anos, precisamente os anos do início da actual crise económica. Podemos colocar a hipótese de que os primeiros a ser despedidos são os temporários e, por isso, o seu número diminuiu nestes anos, caracterizados pela crise económica e pelo aumento do desemprego. Em todo o caso, há que ter em atenção que o volume dos contratos temporários é apenas um indicador da precariedade no emprego.

Observando os resultados por país, podemos constatar que, no contexto europeu, Portugal apresenta uma das mais altas percentagens de precários no conjunto da população empregada. Mais concretamente, Portugal é o 3.․ país da União com uma maior percentagem de contratos temporários, com um valor de $22,3 \%$, correspondendo 
a 883 mil casos. Com números superiores situam-se a Espanha com 27,9\%, e a Polónia com 26,9\%. A média da UE fica-se pelos 13,8\% (Massarelli, 2009: 6, com base em dados do Eurostat e valores de 2008). Os dados do primeiro trimestre de 2010 (Eurostat, 2010) não alteram significativamente a posição relativa dos países, Portugal apresenta um valor de 23,2\%, sensivelmente mais $1 \%$ que em 2008, a Espanha e a Polónia decrescem para $24,4 \%$ e $25,9 \%$, respectivamente, com a média comunitária a diminuir para $13,2 \%$.

Além disso, Dornelas et al. (2010: 26-27) chamam a atenção para o trabalho por conta própria $^{10}$, muitas vezes sob a forma de recibos verdes e configurando situações de precariedade ilegal, onde Portugal apresenta valores muito superiores à média comunitária (UE 27), 22,8\% e 14,9\%, em 2009, respectivamente.

Rebelo (2004: 50) constata que, em Portugal, de 1992 a 2000, os contratos de trabalho não permanentes passaram de 390,7 mil para 707,4 mil, um crescimento de $81,06 \%$, contrastando com um crescimento de $0,81 \%$ dos contratos permanentes (tendo como fonte o Inquérito ao Emprego). É certo que, de acordo com os dados citados pela autora, os contratos não permanentes representavam 19,9\% do total dos contratos em 2000 . Mas em 1992 esse peso era de 12,1\%. Estes dados permitem perceber que a quase totalidade do crescimento do emprego por conta de outrem entre 1992 e 2000 se deu com base na contratação precária. Valores apresentados por Kovács (2005b: 24), e referentes ao período de 1997 a 2002, permitiram à autora afirmar que a criação líquida de empregos tem assentado em empregos temporários. Sendo que esta tendência se mantém no estudo do Observatório das Desigualdades, com dados de 2000 a 2009 e referentes aos contratos a termo certo das empresas privadas (OD, 2011).

A questão que se coloca, então, parece ser mais de fluxo, isto é, de novas contratações em situação de precariedade, do que de stock, isto é, do número de precários no total dos contratados, num contexto em que Portugal apresenta indicadores de emprego precários bem acima das médias da UE.

Contudo, o fluxo afecta o stock, na medida em que, se os novos contratos são quase todos precários, o seu peso no total de contratos aumenta, algo que pode ser potenciado pelos processos de aposentação, saída de contratados permanentes, substituídos por contratados não permanentes.

Gráfico 2 Contratos não permanentes no total dos contratos, em \%

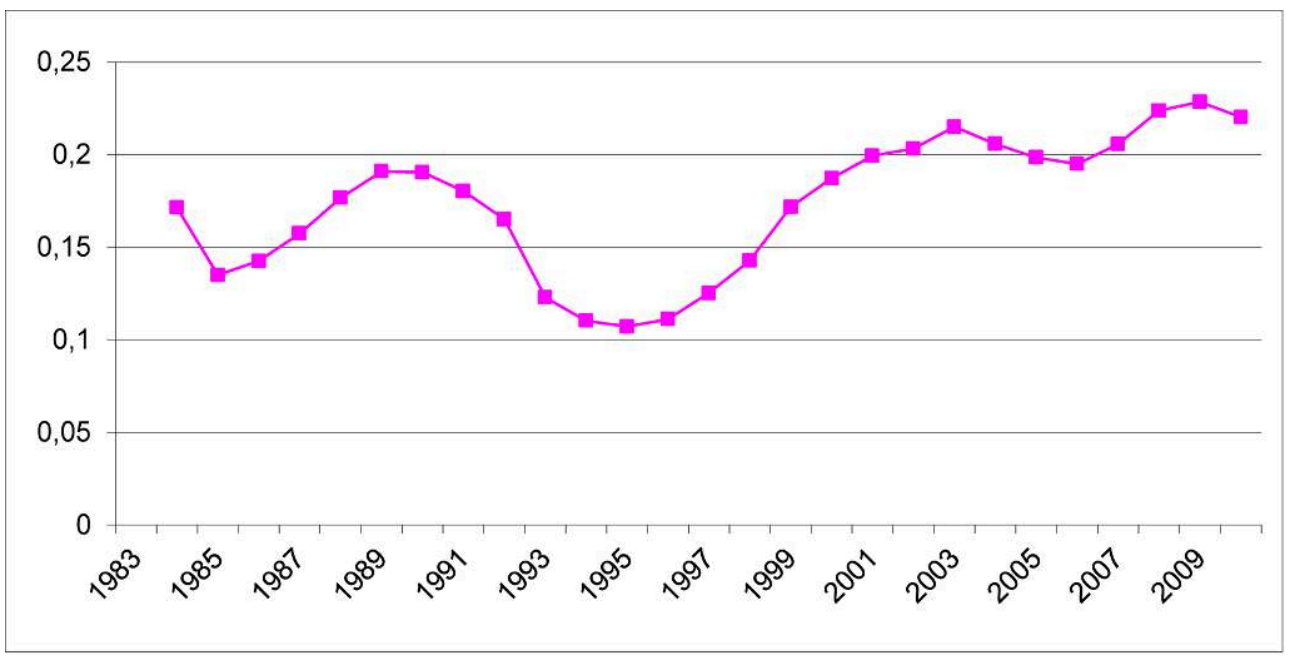

FONTE: Pordata (2010) 
41 Para complementar e actualizar as observações de Rebelo, analisámos uma série mais longa dos contratos não permanentes ${ }^{11}$, um dos grandes componentes do trabalho precário. Nesta, podemos constar que, desde 1983, a tendência é para o aumento desta forma contratual em Portugal, mau grado alguns decréscimos temporários e uma tendência decrescente no último ano da série. Se em 1983 estes representavam 17,14\% do total dos contratos, em 2009 este valor ascendia a 22,02\%. Mais uma vez se nota um acréscimo do peso das situações laborais mais precárias no total dos contratos.

Quadro $1 \%$ da população empregada em Portugal em regime de trabalho temporário, relativamente ao total de empregados, no $1 .^{\circ}$ trimestre de 2010

\begin{tabular}{|l|l|}
\hline & $\%$ \\
\hline Total & 23,2 \\
\hline Homens & 22,6 \\
\hline Mulheres & 23,9 \\
\hline $15-24$ & 55,0 \\
\hline $25-49$ & 23,0 \\
\hline $50-64$ & 10,9 \\
\hline
\end{tabular}

FONTE: Eurostat (2010)

Quem são, como se caracterizam, os trabalhadores em situação de precariedade? Recorrendo aos dados do Eurostat (2010) para Portugal, podemos constatar que a condição de precário é apanágio da maioria dos jovens trabalhadores. A diferença entre homens e mulheres é relativamente baixa. Mais uma vez, os dados indiciam que a questão macrossocial diz respeito ao fluxo, supondo que a maioria dos novos contratos respeita a jovens. Mas também ao efeito acumulado do fluxo no stock.

Relativamente a estudos sobre o assunto, capazes de nos ajudar a compreender quem são os trabalhadores precários e como se têm construído as suas trajectórias profissionais, releve-se a sua quase inexistência ${ }^{12}$. Destaca-se o trabalho de Rebelo (2004: 103 e 156), na sequência da sua tese de doutoramento (Rebelo, 2001: 277 e 338). A autora encontrou um perfil de trabalhador precário em Portugal, mau grado os dados terem sido recolhidos apenas junto de residentes na região da Grande Lisboa (idem: 278), em que as dominantes são o sexo feminino (dado distinto das informações do Eurostat), a desqualificação (escolaridade maioritária até ao 9.ำ ano, sobretudo até ao 6.) e a juventude, à qual acrescenta a ideia de uma trajectória de emprego "relativamente acidentada". Anteriormente, Rosa et al. (2000), elaboraram um estudo para o Observatório do Emprego e da Formação Profissional sobre o assunto, mas as limitações existentes a) na definição de precariedade, b) na não representatividade dos dados recolhidos e c) no escasso valor absoluto do conjunto dos indivíduos analisados não permitem retirar nenhuma conclusão sobre o perfil dos trabalhadores precários, sendo, sobretudo, um estudo que levanta pistas e realiza uma primeira aproximação a este processo social. No mesmo ano, outra equipa (Santana e Centeno, 2000) realizou 
um estudo sectorial sobre dois segmentos da precariedade, o trabalho temporário e a subcontratação, tendo encontrado um número residual de indivíduos nas duas situações, embora em crescendo de importância (Santana e Centeno, 2000: 7).

Em 2005, uma equipa liderada por Ilona Kovács estuda a precariedade no emprego, a partir do conceito de flexibilidade (Kovács, 2005b: 13). Geograficamente, os dados recolhidos concentraram-se na Grande Lisboa, na área metropolitana do Porto e em Aveiro, tendo o estudo incidido sobre o sector dos serviços (idem: 19) e, dentro deste, sobre algumas populações específicas. Na sua caracterização do emprego temporário em Portugal, a partir dos dados europeus, a autora encontra uma prevalência de mulheres e de jovens (idem: 24).

Mais recentemente, o Centro de Estudos Territoriais do ISCTE (2009) elaborou um estudo sobre "as necessidades em Portugal", onde a questão da precariedade foi abordada em função de uma amostra representativa da população portuguesa. Aliás, releve-se que este acaba por ser a única investigação que abordou a questão da precariedade a partir de duas representatividades, a) a da população portuguesa e b) a das várias formas de precariedade, necessárias para uma descrição fundamentada da questão.

Neste estudo, as autoras consideram que "cerca de $41,3 \%$ dos respondentes têm vínculos passíveis de traduzir condições de alguma precariedade - adicionando-se, à ausência de contrato $(12,3 \%)$, os contratos a termo certo $(20,4 \%)$, os contratos a termo incerto $(6,9 \%)$ e a categoria recibos verdes cumprindo horário $(1,7 \%)(. .$.$) " (CET, 2009:$ $23)^{13}$.

Como Rebelo (2001 e 2004) e Kóvacs (2005a), o estudo do CET encontra como categorias sociais mais afectadas pela precariedade os jovens e as mulheres (2009: 24).

\section{As trajectórias de emprego em carrossel dos precários voláteis}

48 Uma grande vantagem de estudar a precariedade entre as pessoas designadas como pobres radica no facto de, em regra, estes indivíduos serem os mais desprotegidos em termos sociais e os mais afastados da norma no emprego. Analisar os pobres permite, pois, conhecer melhor a relação com o trabalho dos indivíduos classificados nesta categoria social e, sobretudo, conhecer toda a pluralidade de formas que a precariedade assume na nossa sociedade. Assim, optámos por aprofundar a análise empírica recorrendo aos beneficiários do RSI, Rendimento Social de Inserção (RSI) ${ }^{14}{ }^{15}$.

Em termos gerais, a maioria dos beneficiários do RSI que trabalha nos Açores ${ }^{16}$ são homens, constituindo quase $70 \%$ do total. A maioria das mulheres beneficiárias, em idade activa, são domésticas (Diogo, 2007a), não diferindo muito, aliás, da situação geral desta região autónoma onde a taxa de actividade feminina é bem menor que a média nacional (Diogo, 2007b).

Apesar de constituírem uma população relativamente jovem, no que respeita às qualificações escolares, $58,5 \%$ tem o $4 .{ }^{\circ}$ ano ou menos, $84,5 \%$ têm o $6 .$. ano ou menos e apenas $4,4 \%$ tem mais do que o 9. ano. Estão, portanto, bem abaixo da escolaridade obrigatória para as suas idades e, comparativamente com a população dos Açores, as suas escolaridades são substancialmente mais baixas. De notar, que, por sua vez, as escolaridades dos activos açorianos são mais baixas do que a média dos portugueses e estas mais baixas do que as médias da União Europeia e da OCDE (Diogo, 2009). 
51 As profissões que exercem resultam, para boa parte (54,5\%), de processos de autoaprendizagem, quer vendo os outros a fazer, quer através da prática (tentativa e erro). Apenas 5,5\% diz que aprendeu através de formação profissional ou na escola. 0 método tradicional da relação mestre-aprendiz apenas contabiliza 6,9\%, não constituindo, portanto, uma alternativa à escola. Com efeito, a relação de aprendizagem com outros apenas assume algum relevo quando é feita por um dos pais, sobretudo o pai, com $28,3 \%$ do total.

Quando confrontados com a questão de alguma vez terem feito formação profissional em algum momento da sua vida, $78,1 \%$ indicaram que não, pelo que não é por aqui que acedem a um degrau mais elevado numa qualquer carreira.

Em termos profissionais, quase todos desenvolvem a sua actividade em sectores como a construção civil, a agricultura e pescas, os serviços pessoais e domésticos, destacandose, em consequência, as profissões da construção civil como ajudante de pedreiro e pintor, a de cantoneiro de limpeza, de empregada doméstica ou de limpeza, assim como as de pescador e operário agrícola.

54 No que respeita aos indicadores de precariedade, como vimos, o vínculo é o mais básico, já que nos remete para a forma mais elementar de precariedade, a relação com o emprego, enquanto conjunto de direitos, obrigações e regalias em relação ao trabalho.

Neste sentido, apenas dois quintos, $41,9 \%$, se diz efectivo, valor, aliás, algo menor do que o presente nos dados do CET para o conjunto da população portuguesa, 58,7\% (CET, 2009: 23). A maioria, três quintos, tem empregos com formas diversificadas de precariedade. De entre estes, $22,7 \%$ encontram-se envolvidos nas formas mais extremas de precariedade, o trabalho ao dia ou à tarefa. Os trabalhadores a prazo representam apenas $14,8 \%$ do total.

De notar que não é a mesma coisa ter um contrato a prazo ou estar enquadrado numa outra forma contratual como o trabalho ao dia ou à tarefa. Se são situações que têm em comum a precariedade, o contrato a prazo distingue-se pelo facto de a esta forma contratual estarem associadas algumas das garantias típicas do Estado-Providência, ou seja, os descontos para efeitos de reforma, de doença e de desemprego. Nem todos os precários são iguais.

57 Um outro indicador importante da precariedade, se a entendermos como um processo diacrónico, nos termos em que propusemos o conceito, respeita ao número de empregos que os indivíduos tiveram na sua vida. Essa informação não é consultada sem dificuldade e sem ambiguidade e isso devido a duas situações: por um lado, um problema de definição; dadas as formas atípicas de emprego com que boa parte destes indivíduos se relacionam com o mercado de trabalho, é entre esta população que mais se coloca o problema de definição de emprego subjacente às questões formuladas e às respostas dadas. Conscientes destas dificuldades, tentámos organizar a sequência das respostas de forma a apresentar aos entrevistados uma noção de emprego que assegurasse a uniformidade do conceito. Este problema, aliás, perpassa todo o protocolo do questionário realizado, não sendo exclusivo desta pergunta, embora aqui se coloque com mais acuidade.

58 A segunda questão que obriga a cuidados acrescidos na leitura desta variável respeita à tendência para que, ao longo do tempo, os indivíduos se esqueçam dos acontecimentos e/ou lhes dêem uma interpretação diferente da forma como foram vividos ${ }^{17}$. Neste sentido não há qualquer dúvida de que o número de empregos declarado se encontra 
subavaliado, não podendo constituir mais do que uma aproximação ao seu valor efectivo.

Assim, $46,6 \%$ do total declara que teve apenas um ou dois trabalhos remunerados na vida. A maioria teve mais de dois trabalhos, de entre estes assumem relevo os que tiveram três ou quatro trabalhos com $35,8 \%$ e os que tiveram cinco ou mais, com $16,5 \%$.

Finalmente, quando se lhes perguntou se alguma vez tinham sido promovidos no seu trabalho, apenas $9,7 \%$ responderam que sim.

61 Consideramos que fica comprovada a importância da diacronia na análise dos processos de relacionamento com o emprego dos indivíduos em situação de pobreza, na medida em que não apenas a estabilidade no emprego é uma miragem para a maioria, como, mesmo nos casos em que esta existe, não se verifica a progressão que associamos à ideia de carreira.

62 Contudo, a questão da precariedade pode ser complementada analisando outro tipo de dados, desde logo a da duração horária semanal do trabalho, que nos remete para a questão do subemprego, entendido como a ocupação semanal em trabalho durante menos horas que o normal contra a vontade do trabalhador em ter um horário normal.

Neste sentido, a maioria, $67,7 \%$, declara trabalhar normalmente 35 ou mais horas por semana. Contudo, os restantes indivíduos, cerca de um terço, encontram-se em situações em que trabalham com menos regularidade, e para $12,5 \%$ a relação com o trabalho é mesmo esporádica, envolvendo a realização de biscates (ou garetes, no jargão local) e actividades com uma duração semanal ou quinzenal muito baixa. Com esta variável percebe-se que nos encontramos face a situações de precariedade múltipla, não apenas envolvendo vínculos precários como, em muitos casos, não estão asseguradas as horas de trabalho normais. Um caso evidente de subemprego nas margens da sociedade.

\section{Conclusões}

Encontrámos entre a população estudada um relacionamento com o mercado de trabalho que nos permite verificar, desde logo, a sua inserção no mercado de trabalho secundário (Berger e Piore, 1980).

Esta inserção está em boa parte associada a um processo de precariedade na relação com o mercado de trabalho que se pode classificar como de precariedade múltipla. Se boa parte declara vínculos laborais precários, o número de empregos ao longo da vida e, sobretudo, a inexistência de progressão na carreira mostram que boa parte dos beneficiários do RSI nos Açores que trabalham podem esperar, em termos de perspectivas de futuro, uma trajectória de emprego em carrossel, dado que, por muito que mudem de emprego, e até de profissão, não deixarão o mesmo lugar no mundo do trabalho e, por consequência, as suas possibilidades de mobilidade social ascendente são diminutas. Isto num contexto em que a precariedade no emprego se instala no mercado de trabalho como uma forma de vinculação envolvendo um número cada vez maior de trabalhadores.

Por outro lado, a precariedade está não apenas associada às questões de vínculo e da diacronia como, na sincronia, se relaciona com o trabalho por períodos horários menores do que aquilo que é o padrão social dominante contra a vontade do trabalhador, ou seja, com o subemprego. Além disso, a precariedade no emprego que 
encontrámos é, em boa parte dos casos, uma precariedade ilegal, na medida em que os enquadramentos contratuais do trabalho não se encaixam no ordenamento jurídico, e é uma precariedade estrutural.

67 A compreensão da multidimensionalidade destes relacionamentos com o mercado de trabalho é, quanto a nós, a mais-valia da análise da precariedade no emprego para a compreensão dos processos de mudança social, categorização social, mobilidade, construção das desigualdades e obstáculos ao desenvolvimento que perpassam a sociedade.

\section{BIBLIOGRAFIA}

BARBIER, J.-C. (2002), “La précarité de l'emploi en Europe”, Quatre Pages, 53. Acedido em 8 de Junho de 2010 http://www.cee-recherche.fr/fr/publicationspdf/4pages53.pdf.

BARBIER, J.-C. (2005), “La précarité, une catégorie française à l'épreuve de la comparaison internationale”, Revue Française de Sociologie, 46-2, pp. 351-371.

BECK, U. (2005), Risk Society: Towards a New Modernity, Londres, Sage.

BERGER, S. e M. J. Piore (1980), Dualism and discontinuity in industrial societies, Cambridge, Cambridge University Press.

BOURDIEU, P. (1986), "L'illusion biographique”, Actes de la Recherche en Sciences Sociales, 63/63, pp. 69-72.

BOURDIEU, P. (dir.) (1993), La misère du monde, Paris, Seuil.

BRESSON, M. (2007), Sociologie de la précarité, Paris, Armand Colin.

CAPUCHA, L. e M. D. Guerreiro (coords.) (1997), Relatório de avaliação da fase experimental do Rendimento Mínimo Garantido, Lisboa, CIES (policopiado).

CASTEL, R. (1995), Les métamorphoses de la question sociale: une chronique du salariat, Paris, Fayard.

CASTEL, R. (2009), La montée des incertitudes: travail, protections, statut de l'individu, Paris, Seuil.

CET (2009), Necessidades em Portugal: tradição e tendências emergentes, resultados do inquérito por questionário, Lisboa, TESE.

DIOGO, F. (2003), Trabalho e Rendimento Mínimo Garantido: Tensão identitária e (re)produção das identidades sociais, Ponta Delgada, Dissertação de doutoramento apresentada à Universidade dos Açores, policopiado.

DIOGO, F. (2007a), Pobreza, Trabalho, Identidade, Oeiras, Celta.

DIOGO, F. (2007b), "Singularidades do trabalho feminino nos Açores: do macro ao microssocial" in Actas do VI Encontro de Sociologia dos Açores, Ponta Delgada, Centro de Estudos Sociais, pp. 89-101.

DIOGO, F. (2009), “Activos altamente desqualificados e insucesso do sistema de ensino", Comunicação ao Colóquio Desigualdades no Sistema Educativo, Ponta Delgada, Centro de Estudos Sociais da Universidade dos Açores, 22 de Junho. 
DORNELAS, A. (coord.) et al. (2010), Emprego, contratação colectiva de trabalho e protecção da mobilidade profissional em Portugal, Estudo elaborado por solicitação da Ministra do Trabalho e da Solidariedade Social, Lisboa, Policopiado (documento de trabalho).

DUARTE, A. M. (2009), “Significados e contornos sociais da precariedade” in Ferve, Dois anos a Ferver: retratos da luta, balanço da precariedade, Porto, Afrontamento, pp. 43-47.

FULLERTON, A. S. e M. Wallace (2007), “Traversing the flexible turn: US workers' perceptions of job security, 1977-2002”, Social Science Research, 36, pp. 201-221.

GAULEJAC, V. e I. T. Léonetti (orgs.) (1994), La lutte des places, Paris/Marselha, Hommes et Perspectives e Desclée de Brouwer.

KOVÁCS, I. (2005a), “Introdução”, in I. Kovács (org.) Flexibilidade de emprego: riscos e oportunidades, Oeiras, Celta, pp. 1-9.

KOVÁCS, I. (2005b), "Emprego flexível em Portugal: alguns resultados de um projecto de investigação", Flexibilidade de emprego: riscos e oportunidades, Oeiras, Celta, pp. 11-53.

MASSARELLI, N. (2009), Population and social conditions, Labour Market Latest Trends $-4^{\text {th }}$ quarter 2008 data, Bruxelas, Eurostat.

OD (Observatório das Desigualdades) (2011), "Precariedade laboral no sector privado afecta sobretudo os trabalhadores mais jovens (2000-2009)", acedido em 16 de Setembro de 2011 http:// observatoriodasdesigualdades.cies.iscte.pt/index.jsp?page=indicators\&id=210\&lang=pt.

PAUGAM, S. (2000), Le salarié de la précarité, Paris, PUF.

REBELO, G. (2001), Emprego e formas de precariedade da actividade laboral: o caso de Portugal no contexto da UE, Lisboa, Universidade Técnica de Lisboa, Dissertação de Doutoramento, 2 vol., policopiado.

REBELO, G. (2002), "Para uma tipologia da precariedade da actividade laboral", Organizações e Trabalho, 28, pp. 69-85.

REBELO, G. (2004), Flexibilidade e precariedade no trabalho: análise e diagnóstico, Lisboa, Fundação Para a Ciência e Tecnologia.

ROSA, M. T. (coord.) et al. (2000), Trabalho precário, perspectivas de superação, Lisboa, Observatório do Emprego e da Formação Profissional.

SAINSAULIEU, R. (1998), “L'identité au travail d'hier à aujourd'hui”, in L'orientation scolaire et professionnelle, 27 (1), pp. 77-93.

SANTANA, Vera e L. Gomes Centeno (coords.) (2000), Formas de trabalho, trabalho temporário; subcontratação, Lisboa, Observatório do Emprego e da Formação Profissional.

SANTOS, B. de S. (1993), “O Estado, as relações salariais e o bem-estar social na semiperiferia: o caso português" in Santos, Boaventura de Sousa (dir.), Portugal: um retrato singular, Porto, Afrontamento, pp. 17-56.

SCHNAPPER, D. (1989), "Rapport à l'emploi, protection sociale et status sociaux", Revue Française de Sociologie, vol. XXX, pp. 3-29.

\section{ANEXOS}

Documentos 
Lei n. 7/2009, de 12 de Fevereiro, Código do Trabalho.

http://www.dre.pt/pdf1s/2009/02/03000/0092601029.pdf acedido em 30 de Maio de 2010.

Internet

EUROSTAT (2010), http://appsso.eurostat.ec.europa.eu/nui/show.do?

dataset=lfsq_etpga\&lang=en

acedido em 14 de Setembro de 2010.

PORDATA (2010), www.pordata.pem acedido em 30 de Julho de 2010.

\section{NOTAS}

1. O autor refere-se a Itália e Espanha (além da França), mas podemos incluir Portugal nesse conjunto, dada a relativa proximidade destes países num grande grupo de variáveis-chave. Aliás, os dados do Eurostat permitem verificar proximidade de comportamento no caso da precariedade, como veremos neste artigo.

2. Beck oferece escassas referências empíricas para sustentar as grandes sínteses que apresenta. Além disso, assume um tom rondando o profético sobre a evolução do trabalho na sociedade industrial que, mau grado boa parte dos prognósticos que fez - a primeira edição do seu livro é de 1989 - se terem vindo a verificar, é pouco compatível com o trabalho sociológico (cf. a crítica a este tipo de prognósticos desenvolvida por Castel, 2009: 30 e, sobretudo, 56). Neste sentido, é uma obra que, como muitas outras publicadas por sociólogos e sob a designação de sociologia, se aproxima grandemente da filosofia social. Não obstante, considerando a importante adesão que o autor e este livro em concreto gozam no mundo da sociologia (Castel, 2009: 36), a sua referência é incontornável. Conclui-se, pois, que boa parte das propostas de Beck merecem mais o estatuto de hipóteses de trabalho, de difícil operacionalização, do que de resultados empiricamente fiáveis.

3. Encontrámos, nos nossos trabalhos empíricos sobre a relação com o trabalho dos beneficiários do RSI na ilha de São Miguel, nos Açores, este tipo de importância do trabalho e da família, embora com o primeiro subordinado à segunda (cf. Diogo, 2007a).

4. Indivíduos que trabalham menos horas do que a norma e do que gostariam, com todas as consequências sociais e pessoais que daí advêm.

5. Neste sentido, veja-se a tipologia de formas de relacionamento com o trabalho apresentada por Schnapper (1989), onde o aparecimento destas formas intermediárias entre emprego e não emprego é também discutido.

6. Designadamente situações que, sendo recibos verdes ou avenças, deveriam ter sido contratualizadas como contratos sem termo, dado que correspondem a necessidades permanentes das empresas.

7. Dadas as limitações de espaço deste artigo, optámos por não incluir os temas a) precariedade e desemprego, b) precariedade e mercado de trabalho secundário, e c) precariedade e formação profissional.

8. Disfarçado de estágio, remunerado ou não, de part-time, de prestação de serviços...

9. Mais uma vez colocamos a hipótese de estes decréscimos estarem associados à maior facilidade de despedimento dos trabalhadores temporários, até pela via da não renovação de contratos (juridicamente não é um despedimento, mas os seus efeitos práticos não diferem), no contexto da actual crise económica. De qualquer forma, esta hipótese não explica o comportamento divergente de Portugal.

10. i. e., “(...) trabalho não dependente de relação laboral legalmente subordinada” (Dornelas et al., 2010: 26-27). 
11. Dos contratos não permanentes constam, até 1998 (exclusive), os contratos a prazo, a partir daí incluem também a categoria outras situações.

12. Já em 2001 Rebelo (2001:274) chamava a atenção para a inexistência de estudos sobre a precariedade laboral, quer a nível nacional quer internacional.

13. Note-se que estes valores não são comparáveis com os acima apresentados, dado que se reportam a universos diferentes.

14. Sobre o RSI veja-se, por exemplo, Capucha e Guerreiro (1997) ou Diogo (2007a).

15. Projecto Trabalho e identidade: valores e práticas entre os beneficiários do RSI, coordenado por Fernando Diogo e financiado pela Direcção Regional da Ciência, Tecnologia e Comunicações da RAA.

16. A relação dos beneficiários do RSI com o mundo do trabalho é profusamente referenciada em Diogo (2007a).

17. A este propósito, vejam-se as observações de Bourdieu sobre identidade e processos biográficos (Bourdieu, 1986).

\section{RESUMOS}

O fio condutor deste trabalho é constituído por duas preocupações que se interligam: a primeira, de natureza teórica, tem a ver com a conceptualização do conceito de precariedade no emprego, dando particular atenção à sua adaptação à realidade portuguesa. A situação nacional é distinta de outras, por questões derivadas da legislação específica e da organização social.

A segunda prende-se com a aplicação das construções teóricas desenvolvidas a uma categoria social específica, os trabalhadores beneficiários do Rendimento Social de Inserção, categoria particularmente marcada pela precariedade no emprego e pela situação de pobreza.

The leitmotif of this paper is constituted by two intertwined questions: firstly, a theoretical one related with the conceptualisation of the idea of precarious employment, focussing particularly its adaptation to the Portuguese reality. The national scene is distinct from other cases as a result of the specific regulation and social organization.

With regard to the second topic, we try to apply the theoretical constructs developed on a social category particularly marked by the precarious employment, in order to test them, individuals in poverty, specifically, workers benefiting from the Social Insertion Income.

\section{ÍNDICE}

Keywords: Job precariousness, employment, poverty, National Income Support Program

Palavras-chave: precariedade, emprego, pobreza, RSI

\section{AUTOR}

\section{FERNANDO DIOGO}

Sociólogo, Professor Auxiliar da U. dos Açores, Investigador do CES-UA fdiogo@uac.pt 